\title{
ANACpédia: termos da aviação
}

\section{ANACpedia: aviation terms}

\author{
Camila Souza de Andrade¹, Fernanda Alves e Silva², Gabriella Mikaloski³, Gabriela Pinto Mafra \\ Estagiária de Letras na área de idiomas da ANAC, Rio de Janeiro, RJ, Brasil. camilandrade89@yahoo.com.br \\ 2 Analista Administrativo - Letras. Servidora da ANAC, Rio de Janeiro, RJ, Brasil. fernanda.silva@anac.gov.br \\ ${ }^{3}$ Estagiária de Letras na área de idiomas da ANAC, Rio de Janeiro, RJ, Brasil. gabriellamikaloski@gmail.com \\ ${ }^{4}$ Estagiária de Letras na área de idiomas da ANAC, Rio de Janeiro, RJ, Brasil. gabi.mafra@hotmail.com
}

Trabalho realizado na ANAC - Agência Nacional de Aviação Civil, Unidade Regional Rio de Janeiro, RJ, Brasil.

\begin{abstract}
RESUMO
Este artigo pretende apresentar a ANACpédia, base de dados formada por vocabulário da área de aviação, em forma de listas de termos, compondo dois glossários bilíngues (inglês-português/português-inglês; espanholportuguês/português-espanhol) e uma lista de siglas em inglês, desenvolvida por servidores da ANAC - Agência Nacional de Aviação Civil do Brasil. Inicialmente imaginadas para suprir necessidades linguísticas do público interno da ANAC, as listas foram disponibilizadas também na Internet possibilitando consulta à comunidade aeronáutica brasileira e internacional.
\end{abstract}

PALAVRAS-CHAVE: Aviação; terminologia; inglês; espanhol; siglas

\section{ABSTRACT}

This article aims at presenting ANACpedia, which is composed of lists of aviation vocabulary that compose two bilingual glossaries (English-Portuguese/Portuguese-English; Spanish-Portuguese/Portuguese-Spanish) and a list of acronyms in English. ANACpedia has been developed by employees of the Brazilian Civil Aviation Agency - ANAC firstly to help ANAC's personnel with issues related to translation of terms. ANACpedia was made available on the Internet to benefit the Brazilian aeronautical community as well as the international aeronautical community.

KEYWORDS: Aviation; translation; terminology; English; Spanish; acronyms

Pontifical Catholic University of Rio Grande do Sul Porto Alegre, RS, Brazil

Editor

Thaís Russomano

Microgravity Center PUCRS, Brazil

Executive Editor

Rafael Reimann Baptista

Faculdade de Educação Física e Ciências do Desporto, PUCRS, Brazil

e-ISSN: $2179-703 X$
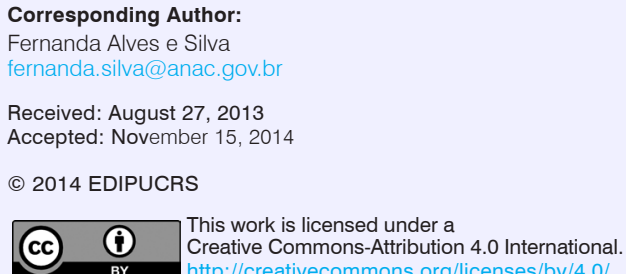


\section{Introdução}

Este artigo pretende apresentar a ANACpédia, uma base de dados composta por vocabulário da aviação, em forma de listas de termos ${ }^{1}$, compondo dois glossários bilíngues (inglês-português/português-inglês; espanholportuguês/português-espanhol) e umas lista de siglas em inglês, desenvolvida por servidores da ANAC Agência Nacional de Aviação Civil do Brasil.

Os glossários reúnem termos e siglas característicos da produção textual da aviação no Brasil e no exterior, o que garante que os termos escolhidos foram retirados de contextos reais de ocorrência. Ou seja, os cenários comunicativos são reais, o que impede a presença de termos "fabricados" e não naturais.

O objetivo inicial e primordial da ANACpédia é auxiliar seus consulentes na compreensão da terminologia de aviação veiculada em língua inglesa e espanhola, e, como consequência, facilitar a produção textual na língua de chegada - o português.

Os glossários estão disponíveis na Intranet da Agência e no Portal da ANAC na Internet (http:// www2.anac.gov.br/anacpedia/).

\subsection{Histórico}

A ANACpédia, ainda com o nome de Glossário de Aviação, foi iniciada para suprir as necessidades do efetivo do extinto DAC - Departamento de Aviação Civil, órgão do Comando da Aeronáutica responsável pela Aviação Civil brasileira antes da criação da ANAC. As necessidades dos colaboradores do DAC relativas ao entendimento e tradução de textos redigidos em língua inglesa e língua espanhola eram bastante representativas.

A partir da necessidade de compilação de termos e expressões relacionados à aviação civil em inglês e espanhol, bem como sua tradução para o português, os objetivos estabelecidos foram:

- auxiliar e facilitar o trabalho de profissionais cujas atividades englobavam as áreas de tradução, versão e redação de documentos variados em línguas inglesa e espanhola;

\footnotetext{
1 Preferimos o uso de "termo" ao invés de "palavra", pois esta última está ligada ao ambiente textual, enquanto que "termo" está ligado ao ambiente pragmático da linguagem, isto é, "importam as implicações pragmáticas que são agregadas à circulação de determinadas unidades terminológicas em alguns campos profissionais. Notadamente, este é o caso de comunicações que objetivam estabelecer uma forma de ação regulando, por exemplo, fazeres legais, normativos, administrativos, estratégicos, operacionais, entre uma ampla gama de possibilidades concretas, seja em contextos públicos ou privados" (Krieger, 2000). No âmbito da ANAC, encontramos unidades terminológicas pertencentes a variados campos de atuação da Agência, tais como: normativo, administrativo, legal, estratégico, operacional etc.
}

- auxiliar os profissionais na produção de textos (com base em informações oriundas de documentos redigidos em inglês ou espanhol).

Durante análises da documentação produzida, foi percebido que cada servidor traduzia livremente termos ou siglas, o que gerava confusão terminológica nos textos. A partir desta constatação, alguns servidores especializados nas áreas de Letras e Linguística, com ajuda da equipe da Biblioteca da ANAC, decidiram compilar palavras, termos e siglas e suas respectivas traduções (oficiais ou não), para posterior tratamento linguístico com fins, a princípio, de unificação terminológica.

No momento da disponibilização das informações ao público, optou-se por uma ferramenta online devido à evidente vantagem dos materiais de referência disponíveis por este meio. Se comparados às obras impressas, os dicionários/glossários/bases de dados eletrônicos online possibilitam consulta mais rápida, busca mais refinada, espaço ilimitado para armazenamento de dados e aspecto visual mais agradável.

O diferencial entre "eletrônico" e "eletrônico online" também deve ser destacado, uma vez que esta última categoria possibilita atualizações constantes, integração de outros recursos (som, imagem etc.) e interatividade com o usuário.

\section{Considerações iniciais}

\subsection{Critérios importantes}

O conceito de listas de termos embasou a elaboração do trabalho desenvolvido pela equipe ANACpédia. Para cumprir com os objetivos iniciais das listas de termos, é importante empregar, idealmente, os seguintes critérios (Teixeira, 2008, p. 207):

a) utilizar, como base de coleta dos termos, textos publicados;

b) utilizar textos completos (porções distintas podem conter terminologia distinta);

c) o autor do texto consultado deve ser competente no assunto;

d) o âmbito deve ser profissional ou educativo;

e) deve-se considerar a data de publicação do texto;

f) a função do texto deve ser informativa, didática ou normativa (dessa forma, garante-se consulta a mais contextos explicativos e definitórios);

g) os textos devem, preferivelmente, ter sido escritos por falantes nativos (para que se possa garantir a naturalidade e a autenticidade das unidades de tradução especializadas equivalentes que comporão o dicionário/glossário/base de dados); 
h) os textos devem ter sido "aprovados" pelo públicoalvo (para o caso específico dos tradutores).

Os textos mencionados nos itens a-h são os textos que compõem um corpus linguístico. Segundo Maciel, 2006, p. 9 um corpus é

uma coletânea mais ou menos extensa de textos, completos ou na forma de excertos, de linguagem natural, autênticos, produzidos para comunicação sem a intervenção do pesquisador, preparados para a análise linguística e leitura pelo computador.

No processo de desenvolvimento da ANACpédia, os critérios listados foram basilares para os trabalhos e foram respeitados em sua quase totalidade.

\subsection{Gênero e tipo textual}

Consideramos importante fazer uma breve distinção sobre gênero e tipo textual, uma vez que os textos utilizados durante a compilação dos dados são específicos da área de aviação, sendo, assim, de gênero e tipo específico.

O gênero é determinado pelo contexto social em que o texto se insere: romance, poema, editorial, piada, anúncio, receita, noticiário. Hurtado Albir (2001, p. 637) indica a identificação do gênero a partir de

agrupamentos textuais que compartilham a mesma situação de uso, com emissores e receptores particulares, que pertencem a um mesmo campo e/ou modo textual e que possuem características textuais convencionais, especialmente de superestrutura e de formas linguísticas fixas; geralmente compartilham a(s) mesma(s) função(ões) e o tom textual.

O tipo textual refere-se ao propósito retórico principal de um texto, ou seja, argumentar, informar, expressar, persuadir, descrever etc. (cf. Colina, 1997, p. 336).

\subsection{A Linguística}

Em termos gerais, a linguística pode ser sincrônica: estudo da linguagem em um dado ponto do tempo (geralmente o presente); ou diacrônica: estudo da evolução da linguagem através do tempo.

Os linguistas procuram estudar o que as pessoas efetivamente fazem nos seus esforços para se comunicarem usando a linguagem. Entendemos que não é objeto de estudo dos linguistas o que as pessoas deveriam fazer, mas sim o que ocorre nos eventos reais de comunicação, seja ela escrita ou oral. Atualmente, a maioria dos linguistas procura clarificar a natureza da linguagem sem usar juízos de valor ou tentar influenciar o seu desenvolvimento futuro.

Uma comprovação da importância do estudo da linguagem como ela acontece nos eventos de comunicação está no fato de que aquilo que, para um determinado grupo de indivíduos é uso incorreto, para o outro é uso idiossincrático (ou apenas o uso de um subgrupo particular - geralmente menos poderoso socialmente).

A Sociolinguística é o ramo da linguística que estuda a relação entre a língua e a sociedade.

A Linguística aplicada é um campo interdisciplinar de estudo que identifica, investiga e oferece soluções para problemas relacionados à linguagem da vida real. Alguns dos campos acadêmicos relacionados à linguística aplicada são: educação, linguística, psicologia, antropologia e sociologia.

\subsubsection{Linguística de Corpus ${ }^{2}$}

A Linguística de Corpus (LC) é uma metodologia utilizada em trabalhos terminológicos. Além de metodologia, a LC pode ser considerada uma abordagem teórica. Como sugere Finatto (2007), a LC deve ser vista também como uma abordagem teórica, pois inclui uma visão de língua harmonizada com a perspectiva comunicativo-textual da Terminologia Textual.

$\mathrm{Na}$ prática, a LC utiliza corpora de uma área específica como base para a criação de materiais de referência, tais como dicionários monolíngues ou multilíngues, glossários, bases de dados terminológicas etc. Segundo Maciel (2006, p. 4), a utilização de corpora na pesquisa linguística permite adotar atitudes não radicais frente aos conceitos fundamentais da teoria linguística.

As pesquisas realizadas com base em corpus envolvem: intuição + habilidade de interpretação + conhecimento do sistema da língua (por parte do falante nativo, do não nativo proficiente ou do linguista).

A visão mais empirista da linguagem, defensora do pressuposto de que se deve observar o que é usado pelos falantes, buscando-se avaliar a frequência e a ocorrência de itens lexicais para posteriormente relacioná-los a outras instâncias da comunicação, é uma das correntes mais significativas no âmbito da LC (cf. Teixeira, 2008, p. 155).

O pesquisador, ao utilizar o corpus para embasar seus estudos, deve levar em consideração os seguin tes preceitos da LC, apontados por Teixeira, 2008, p. 38:

\footnotetext{
${ }^{2}$ A título de curiosidade: o primeiro dicionário de língua inglesa compilado segundo os preceitos da LC foi o Cobuild English Dictionary (Sinclair et al., 1987).
} 
1. Palavras, separadas por espaços em branco, não constituem unidades necessariamente (e, portanto, não são os melhores itens para compor, por exemplo, a lista de entrada de um dicionário);

2. O sentido das palavras depende do contexto em que ocorrem, com o qual formam uma unidade;

3. A ocorrência de uma palavra num determinado contexto co-seleciona as demais palavras e influencia na determinação de seus sentidos;

4. Combinações recorrentes de palavras específicas dispostas numa certa ordem têm um sentido razoavelmente estável.

Ainda segundo Teixeira (2008, p. 153),

os principais diferenciais dos estudos em LC, que vêm atraindo a atenção de pesquisadores dos mais variados campos, são: i) as pesquisas são empíricas: analisam os padrões de uso em textos autênticos, produzidos naturalmente; ii) são utilizadas grandes quantidades de dados, criteriosamente organizados (=corpus); iii) o computador é usado extensivamente nas análises; iv) os estudos empregam técnicas quantitativas e também qualitativas. (Biber, Conrad e Reppen, 1998, p. 4)

\subsubsection{Lexicologia}

A Lexicologia é um ramo da linguística que tem por objetivo o estudo científico do acervo de palavras de um determinado idioma (léxico), de acordo com diversos aspectos. Para isso, procura determinar a origem, a forma e o significado das palavras que constituem o acervo de um idioma bem como o seu uso na comunidade dos falantes. Assim, por meio da lexicologia torna-se possível observar e descrever cientificamente as unidades léxicas de uma comunidade linguística. $O$ pesquisador e especialista da lexicologia é o lexicólogo.

\subsubsection{Lexicografia}

A Lexicografia é a técnica de redação e feitura de dicionários.

Os primeiros dicionários confeccionados eram geralmente bilíngues, glossários que ofereciam traduções de palavras de uma língua para outra. $\mathrm{O}$ período medieval conheceu a produção de dicionários monolíngues, mas geralmente estes dicionários (do tipo tesauro ou thesaurus) não adotavam um arranjo por ordem alfabética; ao contrário, as palavras eram agrupadas conforme o sentido (palavras que diziam respeito às atividades da fazenda, nomes de frutas, e assim por diante). Os primeiros dicionários alfabéticos do inglês não eram completos: eram, ao contrário, compêndios de "palavras complicadas", isto é, de palavras obscuras e difíceis, frequentemente de origem latina. Atualmente, com as contribuições das novas teorias linguísticas e as novas teorias de ensino de línguas a Lexicografia moderna se expandiu. Hoje a preocupação não é apenas em fazer dicionários, mas também, na análise das metodologias de produção lexicográfica, isto é, como e para que os dicionários são feitos. Destaque especial pode ser dado à Lexicografia pedagógica, que estuda os dicionários de aprendizagem de línguas.

\subsection{Terminologia}

Os estudos da terminologia se desenvolveram, de acordo com Auger, 1988, segundo três tendências principais:

- Tendência de orientação linguístico-terminológica $=$ promover a univocidade na comunicação entre especialistas por meio da criação de normas e diretrizes a serem seguidas pelos usuários das terminologias;

- Tendência preocupada com a planificação linguística = aparelhar as línguas regionais em situações de bilinguismo ou coexistência para valorizá-las e preservá-las;

- Tendência voltada para a tradução = muito presente nos países com mais de uma língua oficial, se concentra no estudo e na produção de obras de referência bi e/ou multilíngues.

Sobre a relação terminologia-texto técnico, persiste a concepção errônea comum de que o texto técnico se reduz à terminologia que veicula e serve apenas para transferir conhecimento técnico-científico, sendo desprovido de qualquer forma de estilo ou identidade linguístico-cultural (Korning Zethsen, 1999). No entanto, o texto técnico reflete questões de linguagem, não podendo ser considerado um texto homogêneo, sem polissemias ou ambiguidades.

Em termos gerais, a estruturação de dados terminológicos pode ocorrer segundo as orientações da abordagem conceitual ou da abordagem léxicosemântica.

Segundo L'Homme (2004), a abordagem conceitual não permite integração flexível dos termos e das relações entre os mesmos. A seleção do termo é feita a partir de um único identificador (ou seja, apenas uma palavra). Unidades linguísticas vinculadas a conceitos são selecionadas e o foco permanece nos substantivos. Entretanto, segundo Krieger (2000), "nem sempre o conceito é o único parâmetro para identificar o valor de uma unidade lexical especializada e sim, a implicação pragmática envolvida no conteúdo semântico do termo". Esta abordagem orienta a Teoria Geral da 
Terminologia (TGT), criada por Wüster/escola de Viena, mencionada no item 2.4.1 abaixo.

Em contrapartida, a abordagem léxico-semântica orienta a seleção de unidades que veiculam significado que pode estar relacionado ao assunto ou área em questão (por exemplo, aviação, culinária, mecânica de automóveis, combustíveis etc.). De acordo com LHomme (2004), as unidades lexicais selecionadas podem pertencer a diferentes partes do discurso, contanto que seus significados estejam relacionados à área em questão (podem ser selecionados substantivos, verbos, adjetivos e até mesmo advérbios).

Em relação às concepções antagônicas sobre a constituição e a natureza das terminologias, Krieger (2000) aponta também:

1. Termos técnicos considerados unidades de conhecimento (desconsiderados, portanto, como elementos naturais das linguagens naturais); esta concepção anula a dimensão comunicativa das terminologias; versus

2. Terminologias consideradas unidades lexicais, ou seja, componentes naturais do sistema linguístico.

\subsubsection{Correntes teóricas da terminologia}

- TGT = Teoria Geral da Terminologia (Wüster/ Escola de Viena; Felber e Budin). As metodologias propostas por Wüster eram voltadas para a padronização da comunicação especializada.

- TST = Teoria Sociocognitiva da Terminologia. Para Temmerman (2004 [2001], p. 37), "a terminologia só pode ser estudada no discurso". Suas críticas principais à teoria tradicional são: i) a primazia do conceito sobre o signo linguístico; ii) a preocupação normatizadora que preconiza a relação biunívoca entre conceito e termo e despreza as situações comunicativas e cognitivas de uso da linguagem especializada. Para Teixeira (2008, p. 57), o ponto de partida deve ser o termo (unidade do discurso), e não mais o conceito (unidade abstrata e supostamente definível). Ela defende que somente após a compilação de um corpus textual, a ser selecionado a partir das necessidades do grupo de usuários potencial da terminologia, é que deve-se fazer um levantamento dos termos para posterior coleta de informações (cf. Teixeira, 2008, p. 59).

A ANACpédia dialoga com os seguintes aspectos da TST:

- consideração do público-alvo na seleção e descrição das unidades de interpretação que comporão a obra terminológica;
- o uso mandatório de dados provenientes de corpora textuais, contendo discursos reais.

Socioterminologia ${ }^{3}$. Considera a terminologia em uso (diferentemente da TGT). A Socioterminologia

dedica-se à preservação da identidade linguística e cultural das terminologias, feita por meio da planificação linguística (intervenção na língua no sentido de criar novas terminologias para preencher lacunas de vocabulário, ou para encorajar seu crescimento e desenvolvimento), e tem na variação terminológica seu foco de estudo principal. (Teixeira, 2008, p. 59)

Os autores representativos Boulanger, Gambier e Gaudin afirmam que os termos devem ser estudados "no âmbito das práticas linguísticas e sociais concretas dos homens que empregam tais termos". Para a socioterminologia, há de haver o exame do contexto de produção dos léxicos especializados/terminologia em seu espaço de interação social.

A criação de materiais de referência é tópico amplo, que pode ser tratado e discutido sob diversas perspectivas. Nosso objetivo aqui não é apontar como melhor construir um material de referência ou como reconhecer material adequado para os objetivos do consulente. No entanto, podemos afirmar que a elaboração de instrumentos de referência à luz de princípios socioterminológicos é uma forma de evitar o apagamento das variações que os léxicos terminológicos comportam na diversidade de seus contextos de ocorrência.

TCT $=$ Teoria Comunicativa da Terminologia ${ }^{4}$ (teoria linguística de base cognitiva ${ }^{5}$ e propósito comunicativo). Unidade terminológica (morfema, lexema, sintagma, oração e o próprio texto). Para a TCT, nenhuma unidade lexical pode ser considerada a priori como termo, pois assume esse valor em função de seu uso num contexto comunicativo especializado. Pontos fundamentais da TCT para entender o léxico especializado (Teixeira, 2008, p. 60):

- reconhecer sua poliedricidade (denominativa, cognitiva e funcional);

- sua dupla função (representativa e comunicativa);

- a definição de seus elementos operantes (a linguagem é real, e não ideal; a comunicação deve ser considerada in vivo e não in vitro);

- a diversidade de suas aplicações (de acordo com as características pragmáticas da comunicação).

\footnotetext{
${ }^{3}$ Real funcionamento da linguagem; dimensão social das práticas linguageiras concernidas; exame do contexto de produção dos léxicos especializados.

${ }^{4}$ Nova teoria estruturada pela sobredeterminação dos aspectos comunicativos das linguagens especializadas em detrimento dos propósitos normalizadores.

5 Por preocupar-se com aspectos semânticos da unidade terminológica
} 
O percurso do trabalho terminológico da TCT é semasiológico (do termo para o conceito), e não onomasiológico (do conceito para o termo).

Terminologia Textual. Sua unidade de análise é o texto técnico. $\mathrm{O}$ aporte metodológico mais importante é a Linguística de Corpus. É a linguística do texto especializado (cf. Hoffman, 2004), apresentando postura descritiva.

A atividade de construção de uma terminologia torna-se, antes de mais nada, uma tarefa de análise de corpora textuais. Há duas razões fundamentais para isso: as aplicações da Terminologia são mais frequentemente aplicações textuais (tradução, indexação ${ }^{6}$, redação assistida); a terminologia deve 'vir' dos textos para melhor 'retornar' a eles. É justamente porque ela nunca é desvinculada do texto que se fala em 'terminologia textual'; é nos textos produzidos ou utilizados por uma comunidade de especialistas que estão expressos e, portanto, disponíveis uma boa parte dos conhecimentos compartilhados por essa comunidade; é, pois, por aí que se deve começar uma análise. (Bourigault e Slodzian, 2004 [1999], p. 103, grifo nosso)

\subsubsection{Variabilidade de terminologias}

As terminologias são variáveis dentro de uma área de atividade. Esta afirmação parece paradoxal, a princípio, mas pode ser facilmente explicada se acreditamos que a terminologia está diretamente vinculada às suas aplicações. Ou seja, há tantas terminologias quantas forem suas aplicações. Neste sentido, Bourigault e Slodzian, 2004 [1999], p. 103, destacam:

[...] a constante variabilidade das terminologias se impõe: considerando uma área de atividade, não há UMA terminologia que represente o conhecimento dessa área, mas tantas terminologias quantas forem as aplicações nas quais estas forem utilizadas. Diferem quanto às unidades coletadas e quanto à descrição, conforme a aplicação visada.

\section{Metodologia de elaboração da ANACpédia}

O conteúdo das listas de termos ANACpédia é resultado da interação diária dos profissionais da ANAC com textos da aviação nos três idiomas: português, inglês e espanhol. Ou seja, a extração de termos não é feita por meio de softwares específicos para a extração de terminologia. A equipe ANACpédia realiza levantamentos minuciosos da terminologia de

\footnotetext{
${ }^{6}$ Organizar em forma de índice (bibl).
}

forma "manual", a partir das suas atividades diárias e dos documentos utilizados para o desenvolvimento dos trabalhos da Agência.

A elaboração das chamadas fichas terminológicas ocorre por meio do uso de um software de gerenciamento terminológico, no qual é possível estabelecer campos e relações equivalentes e hierárquicas entre os termos, por exemplo. Foram estabelecidos campos diversos, tais como definição, fonte, sinônimo, nota linguística, nota adicional, dentre outros.

A equipe ANACpédia desenvolve, também, estudos e trabalhos de levantamento de terminologia em subáreas no âmbito da aviação, tais como: manutenção aeronáutica e aeronavegabilidade, operações, infraestrutura aeroportuária, pilotagem de helicópteros etc. A escolha e a priorização dos estudos do vocabulário pertencente a cada subárea depende de fatores diversos, por exemplo, da necessidade de desenvolvimento de trabalhos na subárea em questão e de demandas específicas da ANAC ou do público externo à agência.

As fontes de pesquisa consultadas são as mais diversas possíveis, podendo ser divididas primordialmente em fontes consideradas "oficiais" e "fontes de mercado". De modo geral, entendemos por fontes oficiais aquelas publicadas por autoridades de aviação e aeronáuticas ou autoridades nas áreas de estudo pertinentes (meteorologia, física, mecânica etc.). As "fontes de mercado" são compostas por dicionários, glossários, enciclopédias, obras de referência etc. publicadas por editoras comerciais, chamadas "de mercado". A lista contendo as principais referências bibliográficas utilizadas para as pesquisas ANACpédia pode ser acessada em: <http://www2.anac.gov.br/ anacpedia/>, no link FONTES.

\section{Status atual da ANACpédia}

Disponível na Intranet da ANAC desde junho de 2012 e no Portal da Agência desde setembro de 2013, a ANACpédia tem recebido contribuições diversificadas dos variados profissionais da aviação e de tradutores. A equipe acredita que somente com a contribuição de profissionais especialistas da área o trabalho possa ser constantemente atualizado e melhorado. Assim como em outras áreas de estudo, os subject matter experts desempenham papel preponderante na elaboração de materiais terminológicos na área da aviação.

Desde sua primeira versão disponibilizada em junho de 2012 apenas na Intranet da ANAC, as bases de dados já sofreram diversas atualizações, seja para contemplar as contribuições recebidas ou para ampliar quantitativa e qualitativamente as bases de dados. 
E importante destacar que, durante as pesquisas, identificou-se pequeno número de publicações do tipo na área de aviação. Não há obras publicadas por assunto, tais como Manutenção Aeronáutica, Aeronavegabilidade, Operações etc., e muito menos voltadas para públicos específicos, tais como pilotos, controladores, mecânicos de manutenção aeronáutica, despachantes operacionais de voo etc. As obras disponíveis ainda são quantitativa e qualitativamente insuficientes para as necessidades da área.

É relevante indicar também que a escassez de materiais no mercado é ainda mais crítica em relação à língua espanhola. Praticamente não há dicionários ou glossários contendo traduções, definições, contextualizações etc. nos pares de línguas: espanholportuguês e/ou português-espanhol. E para este idioma, há algumas obras cuja qualidade claramente percebe-se comprometida.

Neste sentido, acreditamos que a ANACpédia possa contribuir como mais uma fonte de referência direcionada à comunidade aeronáutica brasileira e internacional e auxiliar os profissionais da área em suas interações com os idiomas português, inglês e espanhol.

Criada inicialmente para suprir necessidades linguísticas do público interno, a ideia de torná-la disponível ao público externo surgiu apenas em 2011, quando foi percebido que as bases de dados poderiam beneficiar a comunidade aeronáutica brasileira e internacional, e foram disponibilizadas em 2013, após as adaptações necessárias terem sido concluídas.

No que tange à comunidade internacional, a possibilidade de ter a ANACpédia como referência, em especial aos países-membros da CLAC (Comissão Latinoamericana de Aviação Civil), surgiu em junho de 2012, quando o Brasil, ainda como Ponto Focal da Macro-Tarefa Capacitação da CLAC comprometeu-se a disponibilizar as bases de dados na Internet e especificamente autorizar a hospedagem no site da Comissão de um link direto às bases. Ainda, o Brasil e a CLAC comprometeram-se a trabalhar em parceria a fim de constantemente atualizar e melhorar as informações disponíveis, bem como inserir novas informações pertinentes.

\section{Considerações finais}

Com base em nossa experiência de consulta a materiais de referência na área de aviação, podemos afirmar que há uma carência da diversificação dos tipos de obras produzidas a fim de atender necessidades e objetivos variados, de públicos distintos (tradutores, pilotos, especialistas, técnicos, mecânicos, analistas, pessoal de aeroporto etc.).
Neste sentido, a ANACpédia é um trabalho inédito no âmbito desta Agência Reguladora, um passo em direção a pesquisas e estudos especializados na área de linguagem e terminologia da aviação.

A elaboração de materiais de referência tais como dicionários (mono ou multilígues), glossários e bases de dados terminológicos é tópico amplo, que pode ser tratado e discutido sob diversas perspectivas. Nosso objetivo aqui não é apontar como melhor construir um material de referência ou como reconhecer material adequado para os objetivos do consulente. Pretendemos sim que a ANACpédia funcione como um instrumento facilitador à sociedade, em especial à comunidade aeronáutica brasileira e internacional, para que possamos "promover a segurança e a excelência do sistema de aviação civil, de forma a contribuir para o desenvolvimento do País e o bem-estar da sociedade brasileira", missão da ANAC.

\section{Referências}

ALTENBERG, B.; EEG-OLOFSSON, M. Phraseology in spoken English: Presentation of a project. In: AARTS, J.; MEIJS, W. (Ed.). Theory and Practice in Corpus Linguistics. Amsterdam: Rodopi, 1990. p. 1-27.

ARROJO, R. Oficina de tradução: a teoria na prática. 5. ed. São Paulo: Ática, 2007.

AUBERT, F. H. Problemas e urgências na interrelação terminologia/tradução. Alfa, São Paulo, v. 36, p. 81-86, 1992.

AUGER, P. La Terminologie au Québec et dans le monde de la naissance à la maturité. Actes du Sixième Colloque OLFSTQ de Terminologie. 1985, Québec. Québec: Office de la Langue Français et Société des Traducteurs du Québec, 1988. p. 27-59.

AZENHA JR., J. Tradução técnica e condicionantes culturais. Primeiros passos para um estudo integrado. São Paulo: Humanitas FFLCH/USP., 1999.

BARBOSA, H. G. Procedimentos técnicos da tradução: uma nova proposta. Campinas: Pontes, 1990.

BARROS, L. A. (2006). Aspectos epistemológicos e perspectivas científicas da terminologia. Revista Ciência e Cultura, São Paulo, v. 58, n. 2, p. 22-26, abr.-jun. 2006. Disponível em: <http://cienciaecultura.bvs.br/scielo.php?pid-S0009. $67252006000200011 \&$ script $=$ sci_arttext $>$. Acesso em: 11 jul. 2010.

Curso básico de terminologia. São Paulo: Edusp, 2004.

BIBER, D.; CONRAD, S.; REPPEN, R. Corpus Linguistics. Investigating language structure and use. Cambridge: CUP, 1998.

BOURIGAULT, D.; SLODZIAN, M. (1999). Por uma terminologia textual. [Tradução: Sandra Dias Loguercio]. In: KRIEGER, M. G.; ARAÚJO, L. (Org.). Caderno de tradução, Porto Alegre: Editora da UFRGS, n. 17, out.-dez. 2004.

BYRNE, J. Technical Translation: Usability Strategies for Translating Technical Documentation. The Netherlands: Springer 2006. 
BYRNE, J. Análises textual y terminologia, factores de activación de la competência cognitiva en la traducción. In: ALCINA CAUDET, A.; GAMARO PÉREZ, S. (Ed.). La traducción científico-técnica y la terminologia en la sociedad de la información. Castellón: Publicaciones de La Universidat Jaume I, 2002. p. $87-105$.

Terminología: Representación y Comunicación: elementos para una teoria de base comunicativa y otros artículos. Barcelona: Universitat Pompeu Fabra, 1999. (Sèrie Monografies, 3).

COLINA, S. Contrastive Rhetoric and Text-Typological Conventions in Translation Teaching. Amsterdam: Target 9, 1997. p. 335-353.

ENGLE, H. N.; ENGLE, P. Prefácio de Writing from the World: II. Iowa City: International Books and the University of Iowa Press, 1985

FAULSTICH, E. A socioterminologia na comunicação científica e técnica. Revista Ciência e Cultura, São Paulo, v. 58, n. 2, p. 48-51, abr.-jun. 2006. Disponível em: <http://cienciae cultura.bvs.br/scielo.php?script $=$ sci_arttext $\&$ pid $=$ S0009. $67252006000200012 \&$ Ing $=$ en $\& n r m=$ iso $>$. Acesso em: 11 jul. 2010.

FINATTO, M. J. B. Exploração terminológica com apoio informatizado: diálogos entre terminologia e linguística de corpus. In: LORENTE, M.; ESTOPÁ, R.; FREIXA, J.; MARTÍ, J.; TEBÉ, C. (Ed.). Estudis de linguistica $i$ de linguistica aplicada en honor de M. Teresa caré Castellví. Barcelona: IULA, 2007. Vol. 2: De deixebles.

GAUDIN, F. Pour une socioterminologie: Des problèmes pratiques aux pratiques. Institutionnelles. Rouen: Publications de l’Université de Rouen, 1993.

HOFFMAN, L. (1999). Conceitos básicos da linguística das linguagens especializadas. Tradução de Ulla Pedde Muss e Maria José Bocorny Finatto]. In: KRIEGER, M. G.; ARAÚJO, L. (Org.). Caderno de tradução, Porto Alegre: Editora da UFRGS, n. 17 , out.-dez. 2004.

HURTADO ALBIR, A. A aquisição da competência tradutória: aspectos teóricos e didáticos. In: PAGANO, A.; MAGALHÃES, C.; ALVES, F. (Org.). Competência em tradução: cognição e discurso. Belo Horizonte: Editora UFMG, 2005.

- Traducción y traductología. Introducción a la traductología. Madrid: Cátedra, 2001.

KÖNIGS, F. G. Übersetzen im Fremdsprachenunterricht: Theoretische Erwägungen und praktische Anregungen. In: JUNG, U. H. (Ed.). Praktische Handreichungen für den Fremdsprachenlehrer. Frankfurt: Lang, 1992.

KORNING ZETHSEN, K. The dogmas of technical translation: Are they still valid? Hermes, Journal of Linguistics, n. 23, p. 65-75, 1999. Disponível em: < http://hermes2.asb.dk/archive/ FreeH/H23_05.pdf>. Acesso em: 11 jul. 2010.

KRIEGER, M. G. Terminologia revisitada. DELTA, São Paulo, v. 16, n. 2, 2000.

KRIEGER, M. G.; FINATTO, M. J. B. Introdução à Terminologia: teoria \& prática. São Paulo: Contexto, 2004.

LHOMME, M. C. A Lexico-semantic Approach to the Structuring of Terminology. Computerm, 2004. Disponível em: <http://www.ling.umontreal.ca/lhomme/docs/Computerm 2004.pdf>. Acesso em: 11 jul. 2010.

MACIEL, A. M. B. Reflexão sobre a pesquisa terminológica em corpus. In: ENCONTRO NACIONAL DA ANPOLL, XXI., PUC-SP, 19-21 de julho, 2006, São Paulo, SP.

NEWMARK, P. A Textbook of Translation. Hemel Hempstead, UK: Prentice Hall, 1988.

NIDA, E. A. Towards a Science of Translating: With Special Reference to Principles and Procedures Involved in Bible Translating. Leiden: E. J. Brill, 1964.

NORD, C. Translating as a purposeful activity: functionalist approaches explained. Manchester, UK: St. Jerome, 1997.

PAGANO, A.; MAGAlHÃes, C.; AlVES, F. (Org.). Competência em tradução: cognição e discurso. Belo Horizonte: Editora UFMG, 2005.

TEIXEIRA, E. D. A Linguística de Corpus a serviço do tradutor: proposta de um dicionário de culinária voltado para a produção textual. Tese (Doutorado) - Programa de PósGraduação em Estudos Linguísticos e Literários em Inglês do Departamento de Letras Modernas, Faculdade de Filosofia, Letras e Ciências Humanas da Universidade de São Paulo, São Paulo, 2008.

TEMMERMAN, R. (2001). Teoria Sociocognitiva da Terminologia. Tradução de Natacha Enzweiler e Luiza Araújo. In: KRIEGER, M. G.; ARAÚJO, L. (Org.). Caderno de tradução, Porto Alegre: Editora da UFRGS, n. 17, out.-dez. 2004.

VASCONCELlOS, M. A.; PAGANO, A. Explorando interfaces: estudos da tradução, linguística sistêmico-funcional e linguística de corpus. In: PAGANO, A.; MAGALHÃES, C.; ALVES, F. (Org.). Competência em tradução: cognição e discurso. Belo Horizonte: Editora UFMG, 2005.

WILL. F. Literature Inside Out. Cleveland: Western Reserve University Press, 1966.

Endereço para correspondência:

Fernanda Alves e Silva

Av. Presidente Vargas, $850-8^{\circ}$ anda 20071-001 Rio de Janeiro, RJ, Brasil Tel.: (21) 3501-5738

<fernanda.silva@anac.gov.br> 


\section{ANEXO}

\section{ANACpédia: O que é, status atual e disponibilização na Internet}

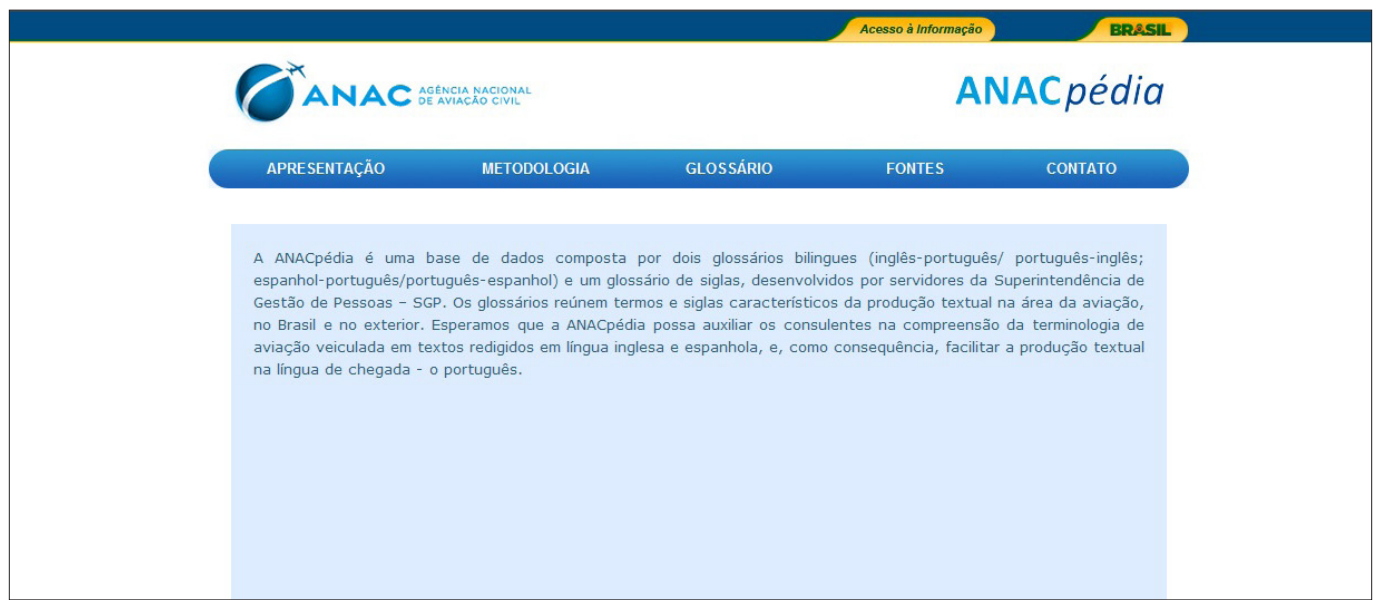

Figura 1 - Tela Inicial ANACpédia

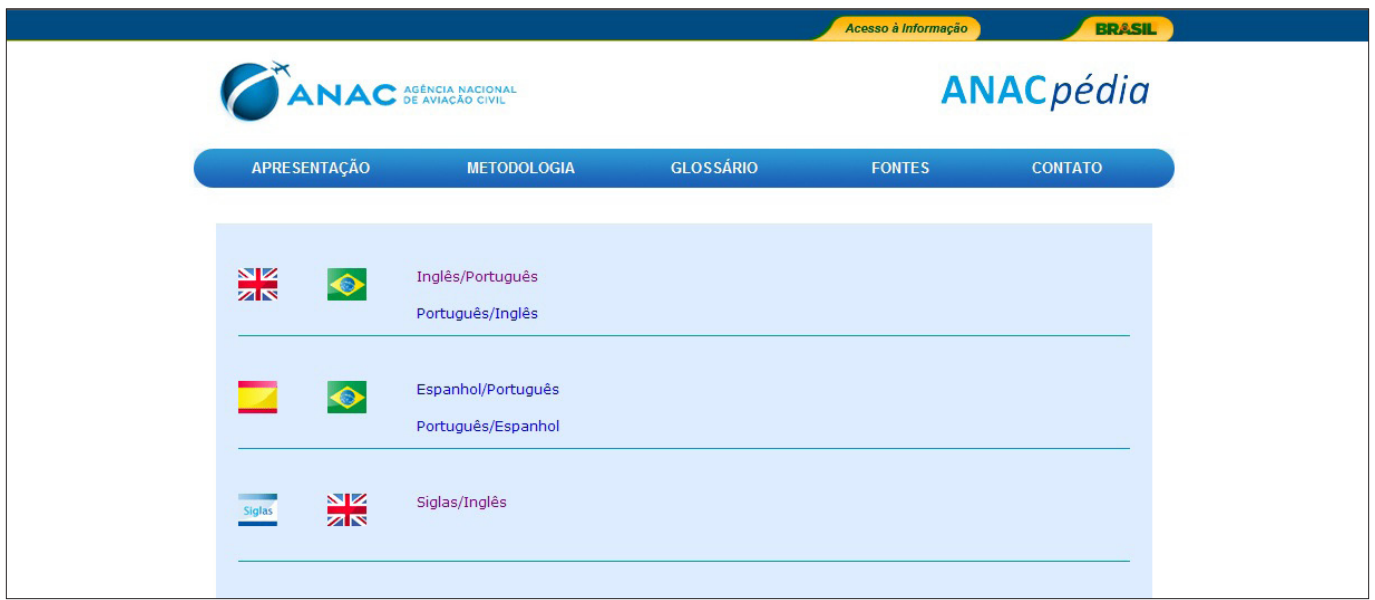

Figura 2 - Tela de acesso às bases de dados

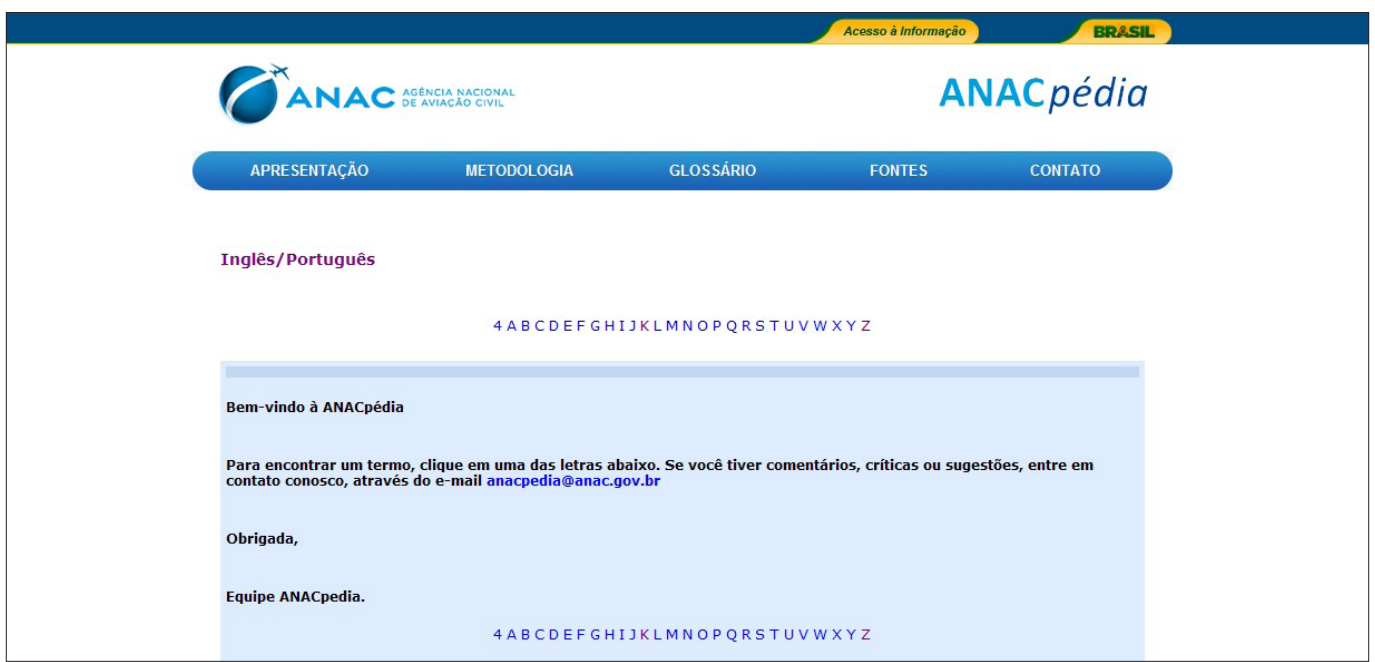

Figura 3 - Tela de acesso aos dados inglês-português 


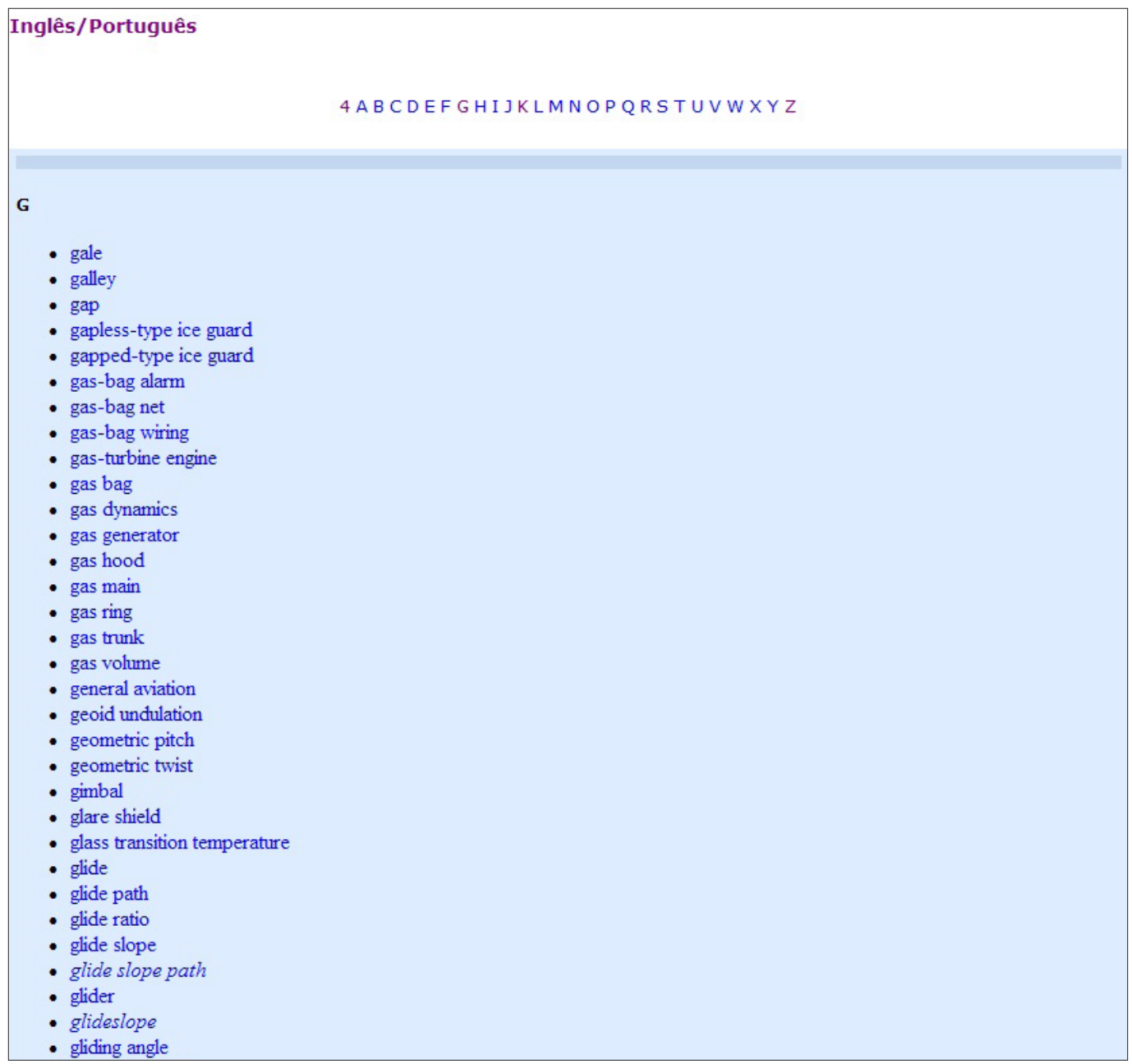

Figura 4 - Tela com a lista de termos da letra "G" a serem clicados pelo consulente

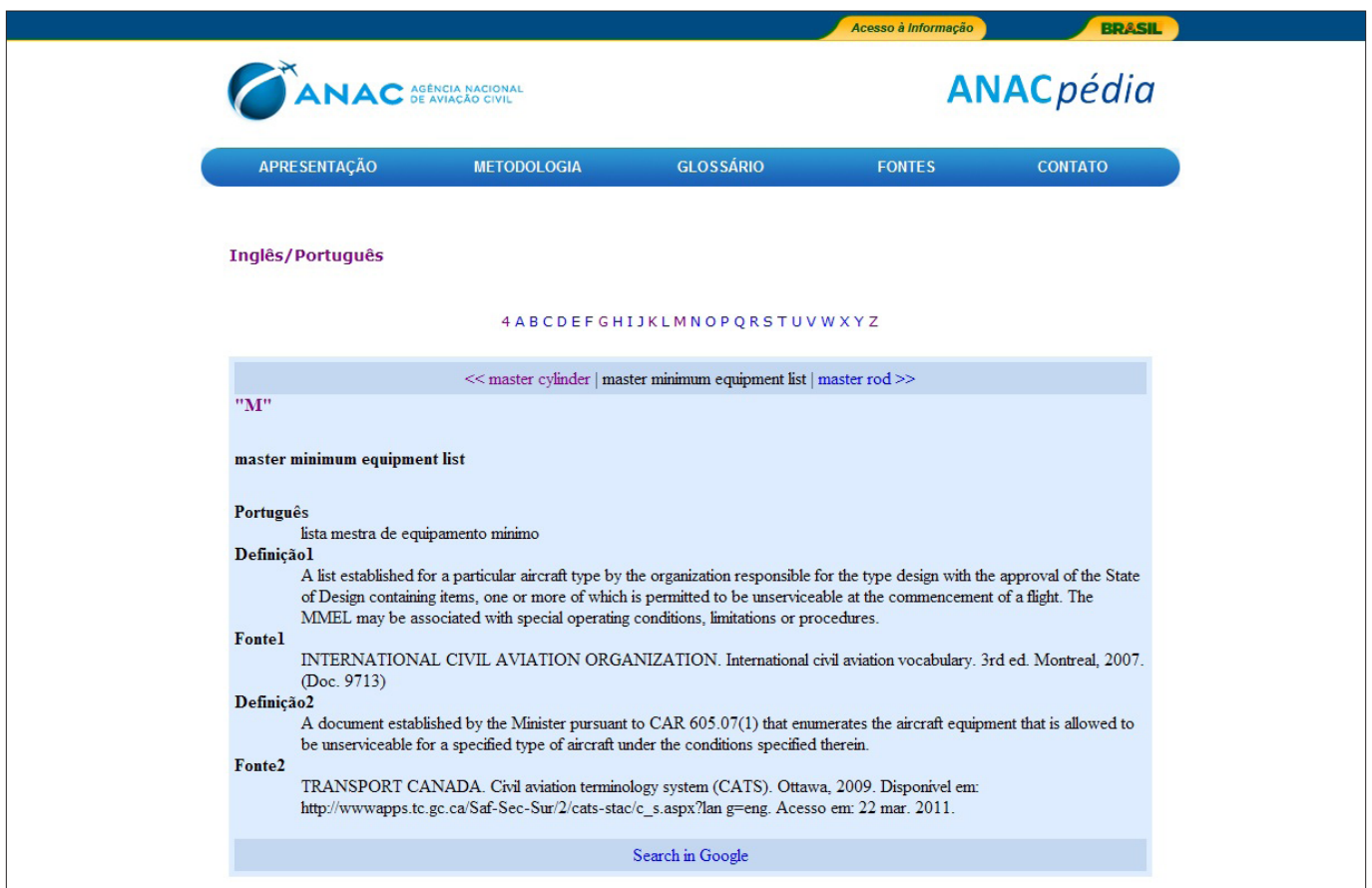

Figura 5 - Tela com as informações disponíveis para o termo "master minimum equipment list" 


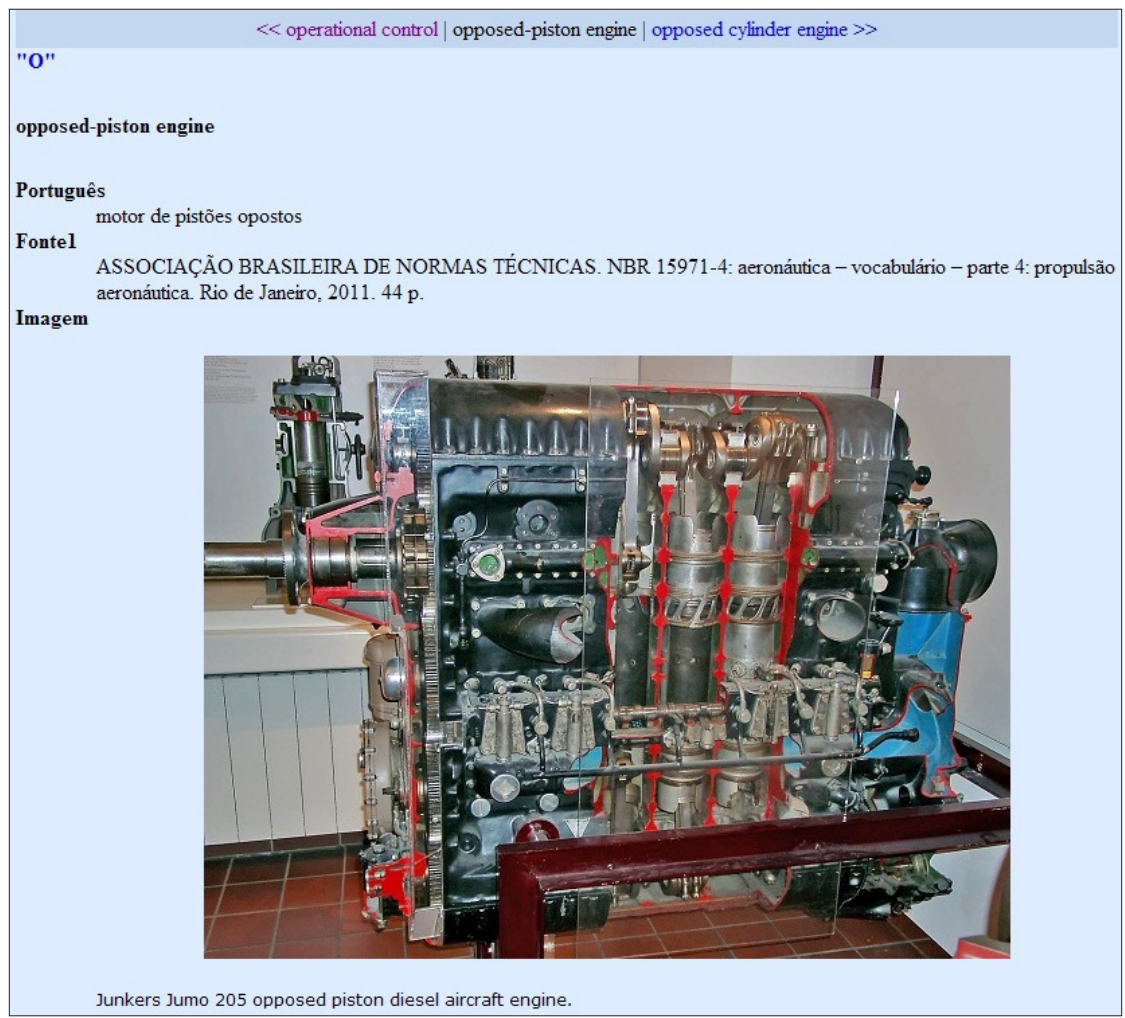

Figura 6 - Tela com as informações disponíveis para o termo "opposed-piston engine"

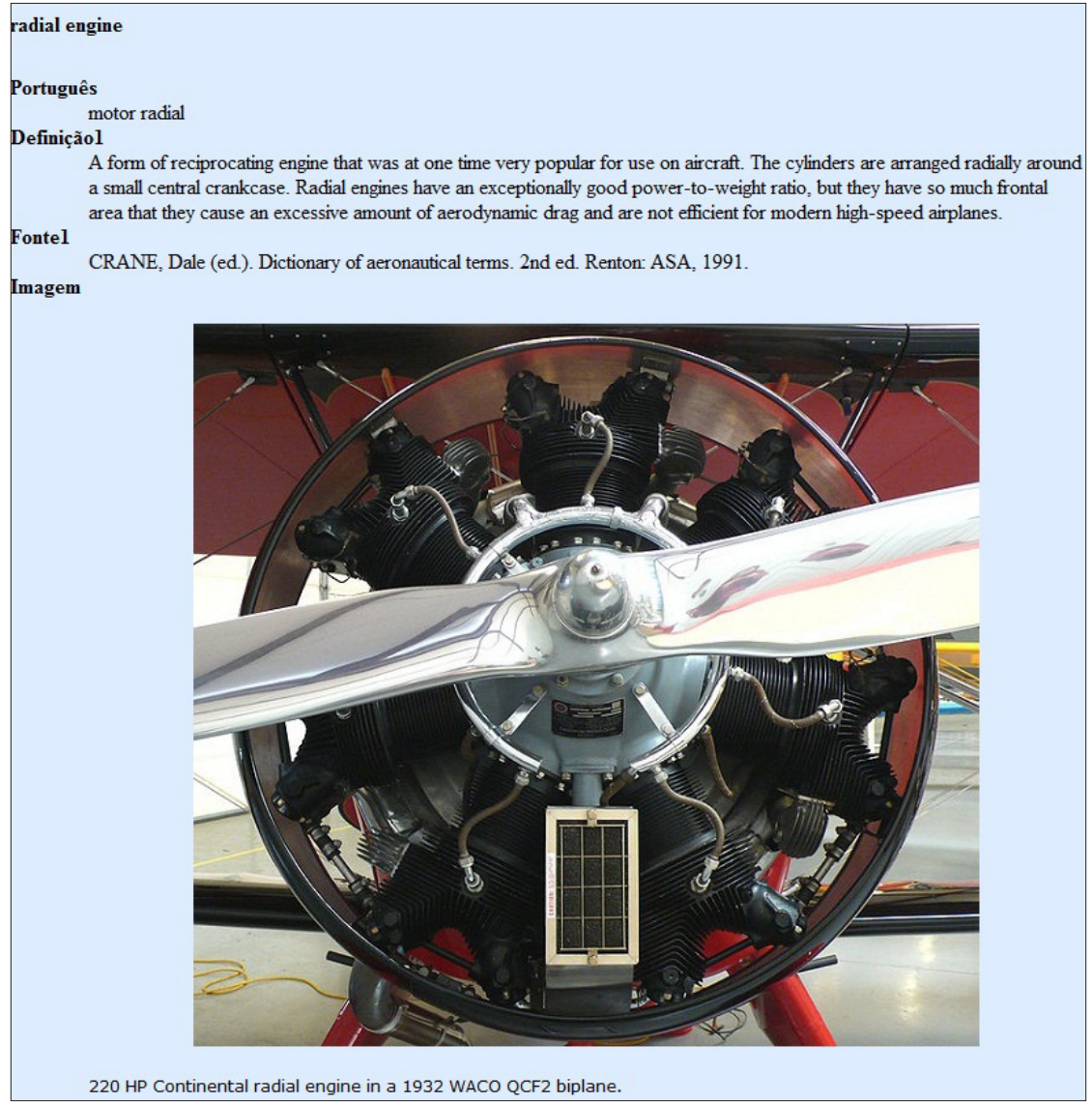

Figura 7 - Tela com as informações disponíveis para o termo "radial engine" 


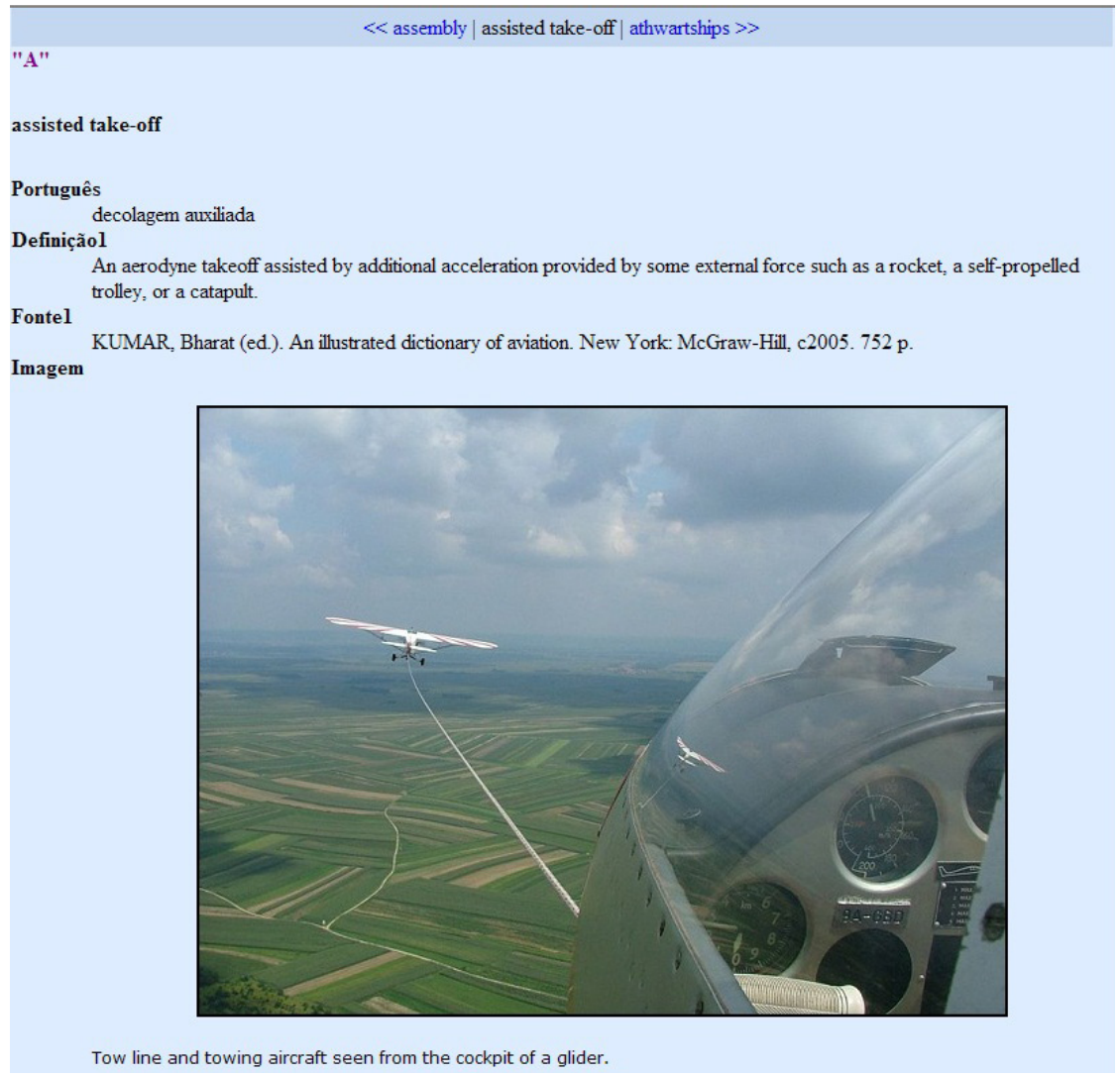

Figura 8 - Tela com as informações disponíveis para o termo "assisted take-off"
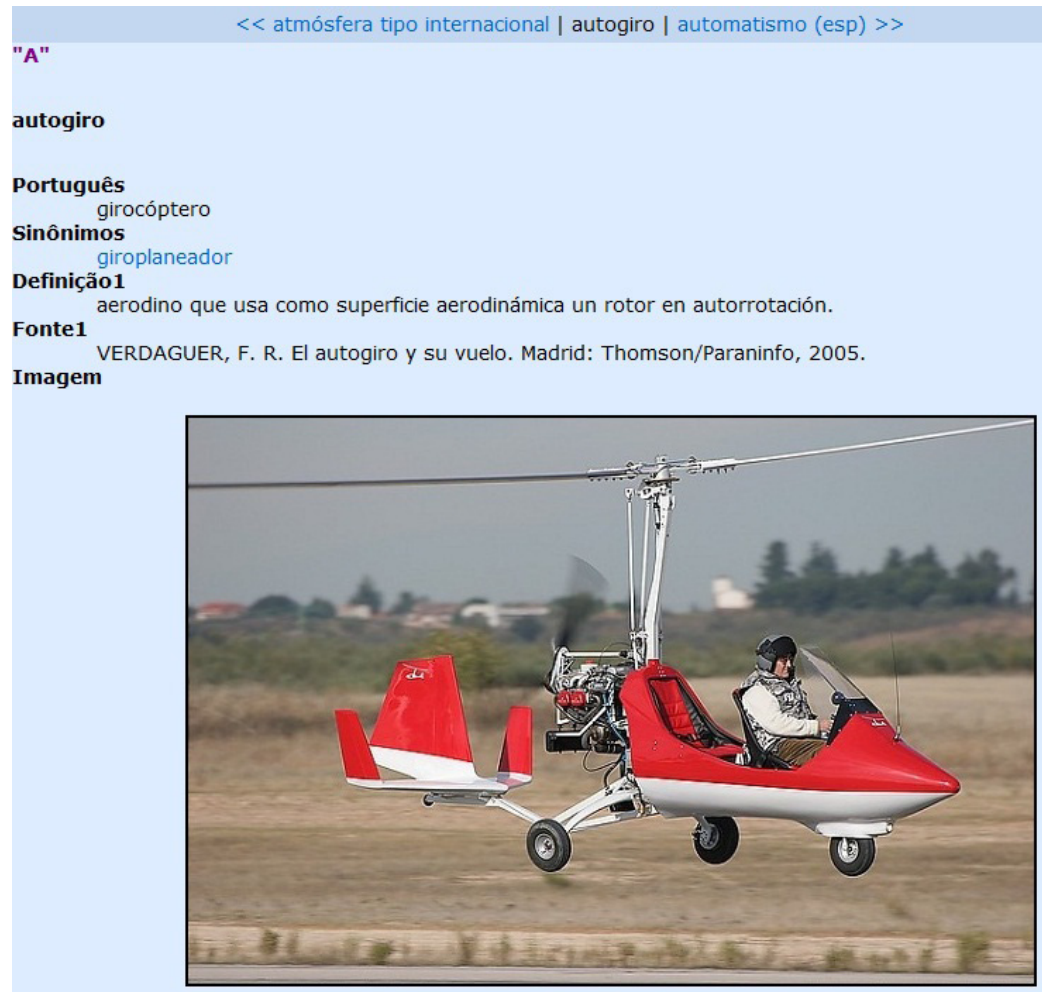

ELA 07, un autogiro moderno fabricado por la empresa española ELA Aviación.

Figura 9 - Tela com as informações disponíveis para o termo "autogiro" (espanhol) 


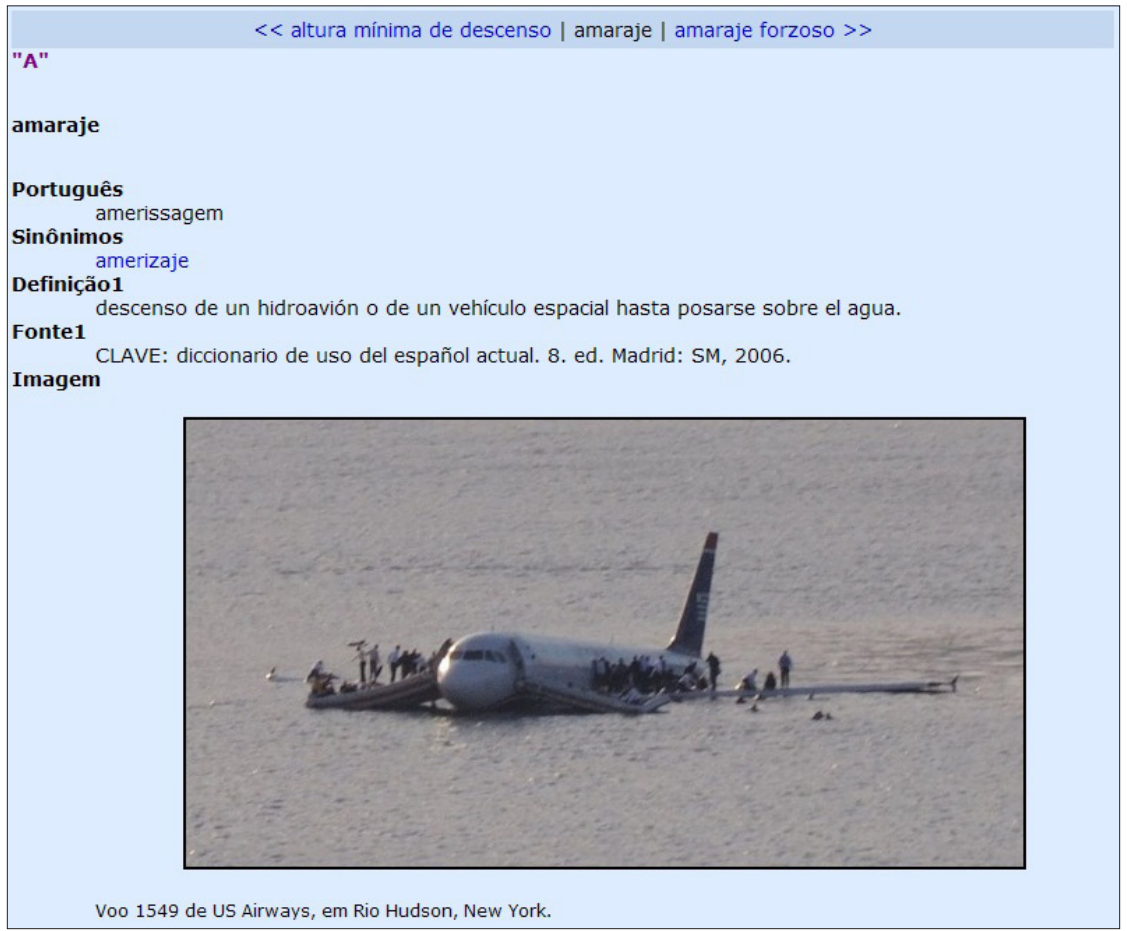

Figura 10 - Tela com as informações disponíveis para o termo "amaraje” (espanhol)

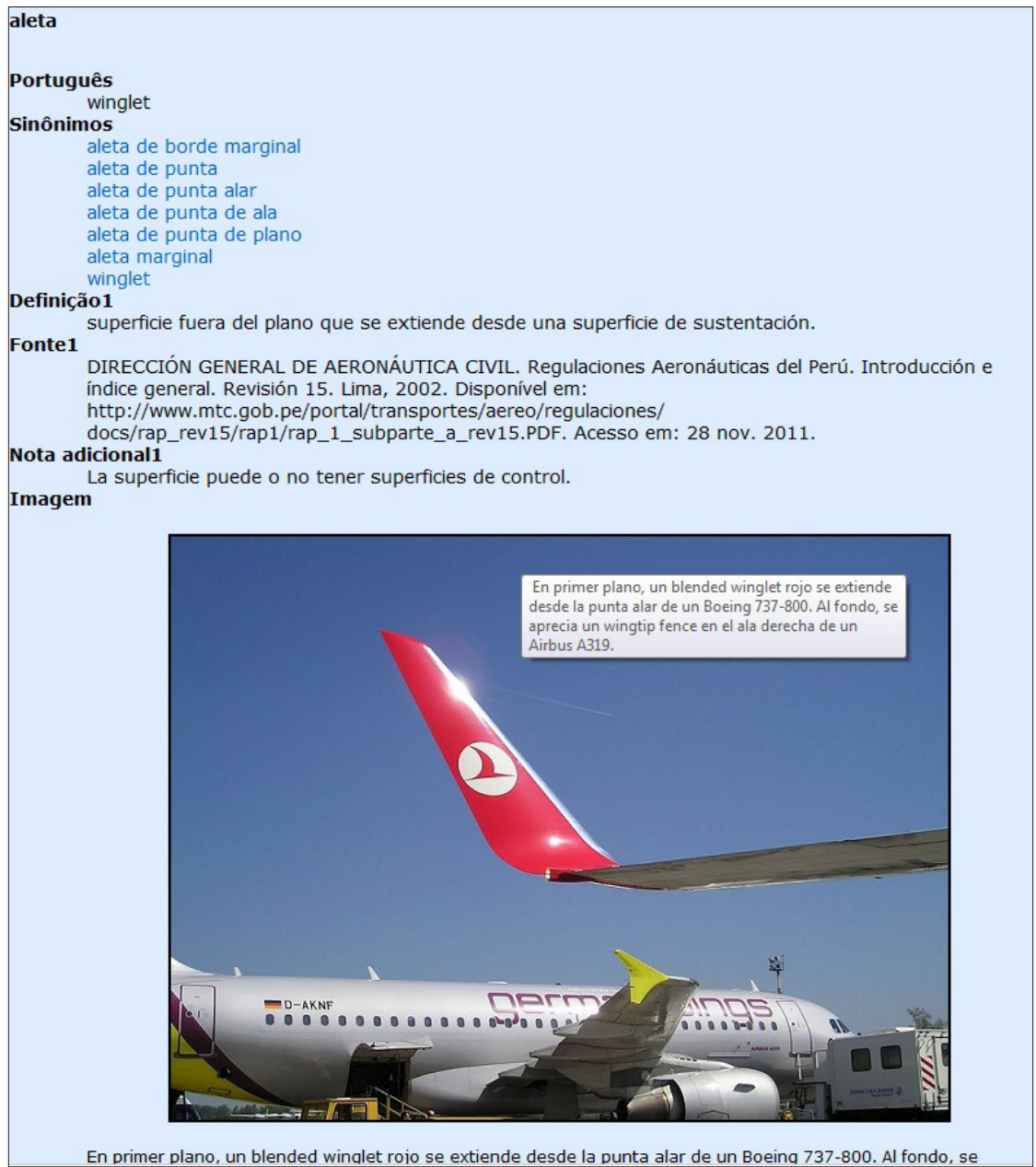

Figura 11 - Tela com as informações disponíveis para o termo "aleta" (espanhol) 


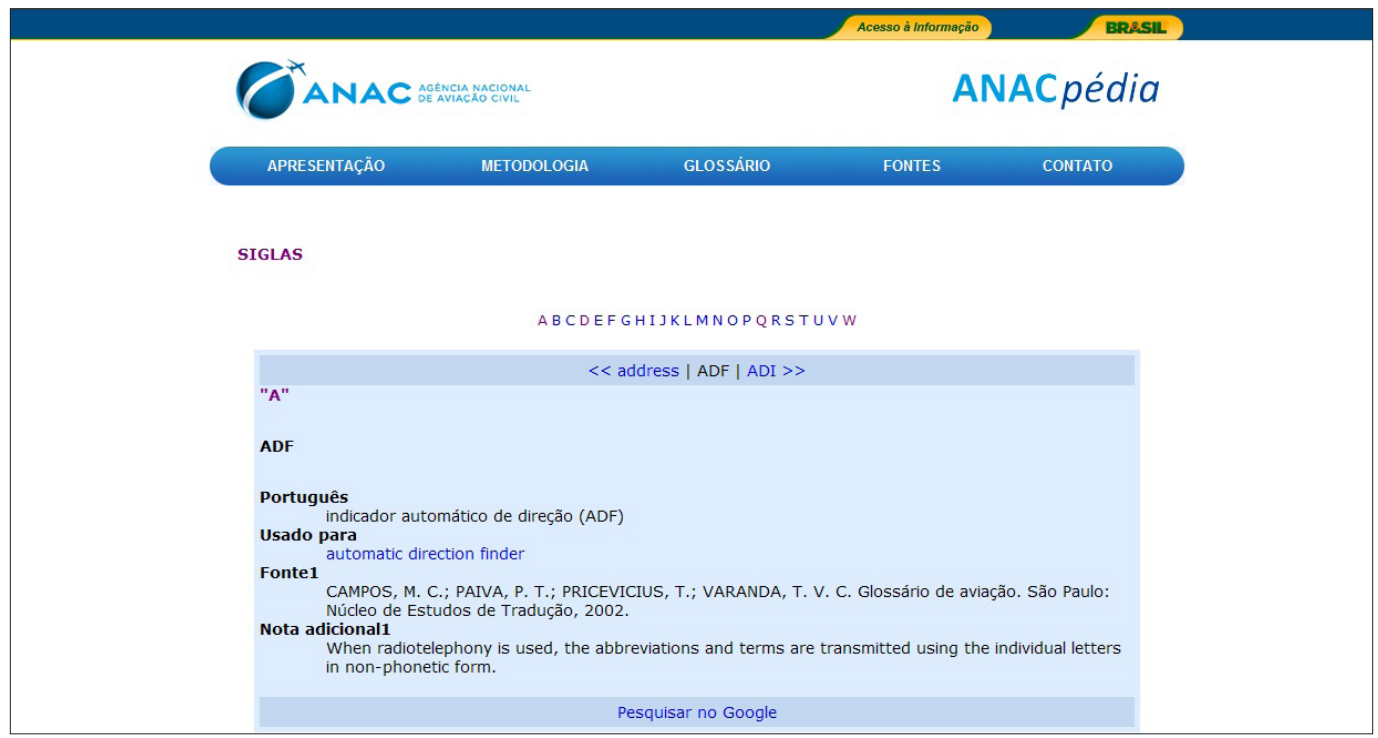

Figura 12 - Tela com as informações disponíveis para a sigla "ADF"

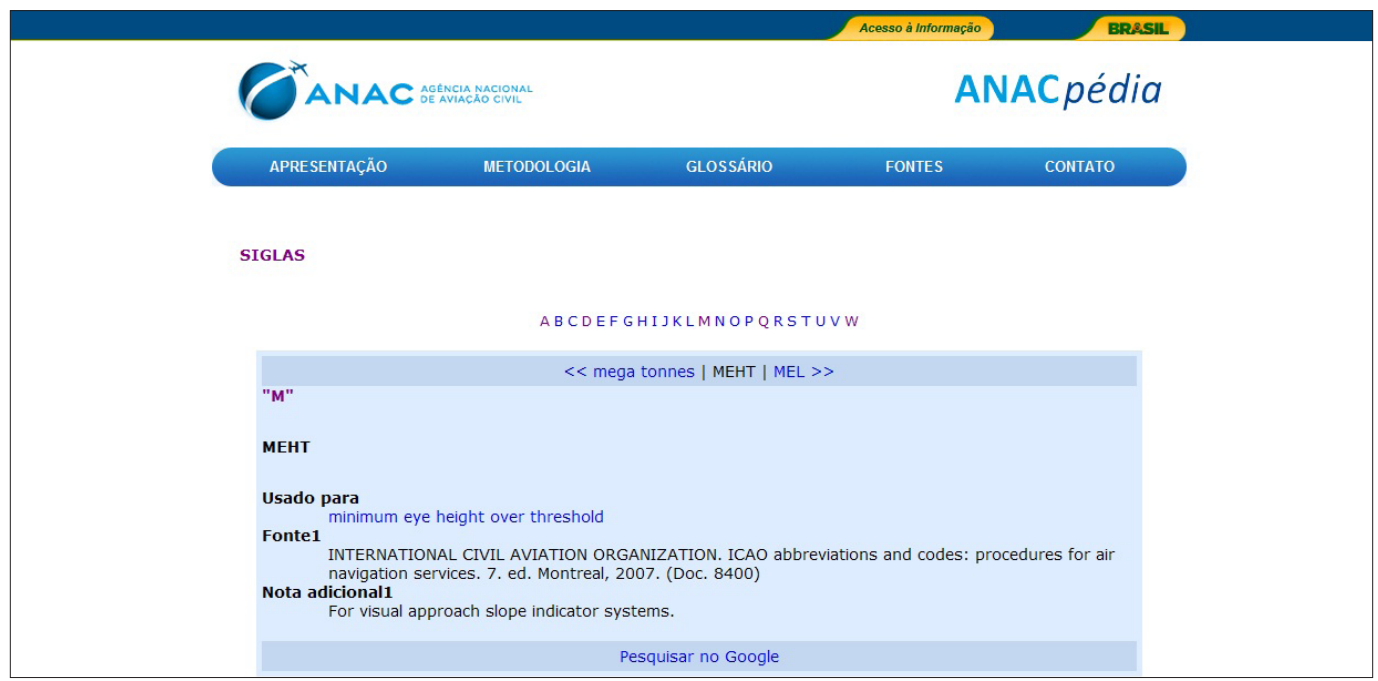

Figura 13 - Tela com as informações disponíveis para a sigla "MEHT" 